\title{
Social and Environmental Accounting, the Corporate Social Responsibility: (Awareness, Benefits and Problems Facing By Sugar Factory in Bidar District, Karnataka, India.)
}

\author{
Bhimasha K. B. \\ Asst. Prof. of Commerce Govt. First Grade College, Manhalli, Tq:Dist: Bidar, Karnataka
}

\begin{abstract}
The social and environmental issues and the impact of them on the decision making process have been increasingly given attention to the financial reporting. Over time there are many studies about Social and Environmental accounting that have different views and arguments on the importance to the corporate report. In developed countries, the social and environmental accounting has joined the financial report and annual report; however it is still a new concept to Sugar factories. The objective of this study is to assess the understanding of Bidar District people on the social and environmental concept, their implementation on factories in Bidar. In order to collect data for the research, questionnaire survey will be used as a helpful method. The finding uncovers that although most people understand the importance of social and environmental activities and having corporate social responsibility reports, few of Bidar factories are able to quantify the cost and benefits of social and environmental activities as in the financial report.
\end{abstract}

\section{Introduction:}

Environmental pollution and social equity are not only the issues of each country, but the general issues of the worldwide. In current period, countries which want to implement the sustainable development objectives must also implement the environmental protection and social welfare programs. Environmental and social protection is the urgent task of each enterprise, each level, each sector, and each country. For any economic sector, the development is always linked to the sustainability of environment and society. In the long term, the responsibilities of the enterprises to the environmental and social issues shall be an important factor to increase the profit of these enterprises. Thus, the enterprises are required to balance between the economic benefits and social and environmental contributions, implementing the responsibilities of the enterprises to the environment through particular actions such as: environmental impact assessment, paying environmental tax, classifying and treating solid waste, minimizing the costs on materials, fuel and reducing the costs for waste. Especially in the background of international economic integration and globalisation, the competition is fierce and fiercer, many enterprises only concern on their short-term benefits and have decisions and actions with negative impacts on the environment; as a result, they have to pay the penalty for their actions when the consumers and the society boycott their products. Corporate Social Responsibility links the responsibilities of the enterprises with the society and links the activities of the enterprises to the strict environmental and social standards, and support the community in different manners. Accordingly, besides the criteria on using advanced, clean, environmentally friendly technologies, reducing carbon gas and toxic substances which may cause bad impacts on the ozone layer, and climate change, enterprises are also required to be transparent in their production and business activities and the leaders of the enterprises should be responsible for explanations to relevant competent authorities. To implement Corporate Social Responsi, first of all, it is required to have high agreement within the enterprise, the conformity to the regulations of the state and local regulations of the enterprises on enterprise administration, local rules on control and audit activities and business ethnic.

\section{Statement of the problem}

Recently the public is watching closely to pressing cases of violating business ethics and destroying the environment and health at serious level such as discharging untreated wastewater (Malai) directly to the Naranja River by sugar factories in Bidar. The wrong-or right of the above cases are clear. However, for the society and thousands of operating enterprises, the issue of Corporate Social Responsibility (CSR) is set up and requires to be discussed seriously in terms of policy argument and practice. What should a company do to be evaluated by the society as a good company with sustainable development? What are the responsibilities of the state management agencies? Which level should the law regulate about the corporate social responsibility? Whether or not the consumers in developing countries have fewer rights and or they are vulnerable or they are not provided with sufficient rights and means or fail to use sufficiently the rights and means given to them to protect their legitimate benefits? Instead of some enterprises which have applied CSR policy and ethnic rules, we normally base on top-down approach while the suppliers apply the ethnic rules when they are required from 
the customers other than they develop CSR themselves to expand their market share. This may require the enterprises to apply many different ethnic rules, depending on the number of customers that they are having transactions, sometimes this is a contradiction. Furthermore, the understanding of the term of CSR in Bidar has considerable changes at national scope and at the enterprises. This will made the application of CSR in Bidar is more passive.

\subsection{Objectives of Research: -}

1. To investigate the understanding of people about CSR and Environmental and Social Accounting in sugar factories.

2. To understand the current implementation of CSR and Environmental and Social Accounting in sugar factories.

\subsection{Scope of Research: -}

Research conducting place: Bidar Sahakari Sakkare Karkane, Ltd. Hallikhed, Bidar District. - Object of the research: managers, employees and customers. Time duration of conducting the research: from October 03, 2012 to October 10, 2012.

\section{Research methodology}

There are two basic methods, qualitative and quantitative. The choices of research methodology depend upon the data collection techniques and data analysis procedures

\subsection{Data sources}

There are two types of data will be collected for this research, which are primary and secondary data.

\subsection{Limitation of the research}

The first limitation of questionnaire survey is that, respondents are chosen randomly in one factory. They can be managers, employees, or customers working in different tasks. Therefore, they could not have sufficient knowledge of SEA or CSR and unable to answer the research questions. Furthermore, the duration to collect the questionnaire is quite short. During that time they can be busy or do not have enough time to answer the question deliberately. They might skim and make fast decisions. Thus, the reliability of the answer might not sufficient.

\section{Data Analysis}

The questionnaire is given to 50 respondents; however, there are only 28 people respond to the questionnaire, 22 other people refuse to answer. The filled-in questionnaire is going to be classified into categories of age, gender, and question $\square \mathrm{s}$ number bases. As the research's intention, this research will study about many selected Factory in Bidar. But in fact, as for the limitation in time and capacity, the research only studies one factory established in Bidar, which is BSSK Ltd. focusing on the producing sugar. This analysis consists of two parts as follows:

4.1. Interpretation and Analysis of Respondents about the Awareness of Social and Environmental Accounting . 4.2. Interpretation and Analysis of Respondents about the Implementation of Social and Environmental Accounting

\subsection{Interpretation of Respondents' information}

When answering the questionnaire, respondents are asked to provide some personal basic information, which are Name, Age, and Gender. With 8 questions sent to 50 people such as managers, employees, customers, receiving 28 results. This information is gathered as follows: 


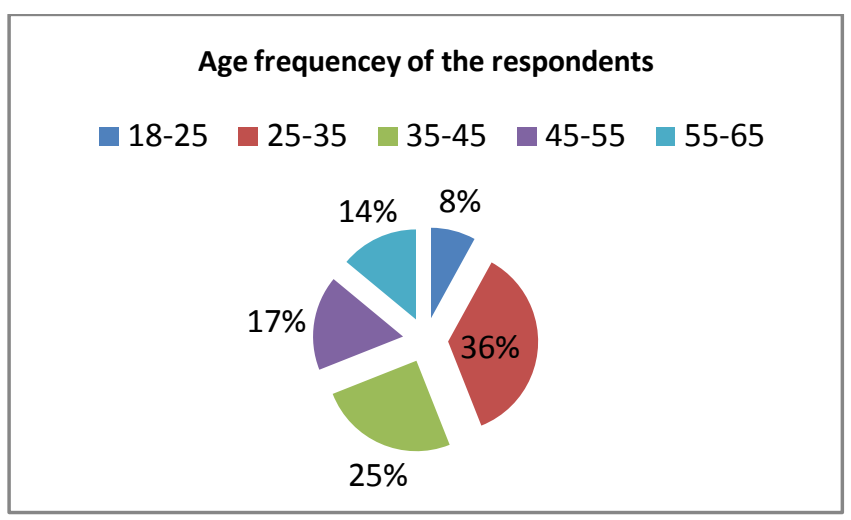

Figure 2: Age frequency of respondents .

Based on collected data, respondents from 18 to 25 years old are 2 people, equal to $8.00 \%$; respondents who are from 25 to 35 years old are 10 people, hold $36.00 \%$. Other respondents are people from 35 to 45 years old, 7 people, as $25.00 \%$; from 45 to 55 years old, 5 people, equal to $17.00 \%$; and from 55 to 65 years old, 4 people, as $14.00 \%$.

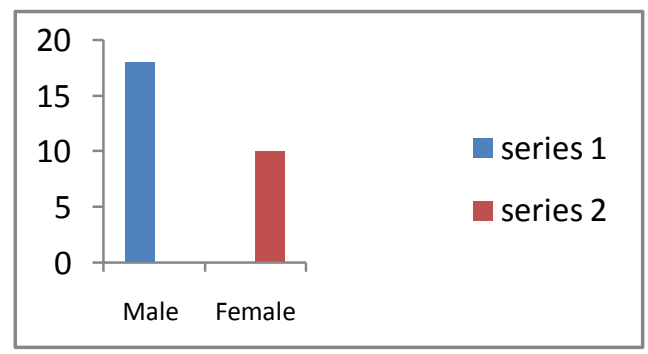

Figure 3: Gender frequency of respondents.

\subsection{The data of respondents $\square$ Gender can be illustrated in chart as follows:}

From the table and chart above, it is easily to see that among 28 respondents, 16 people are male, equals 58.00 $\%$, and the rest, 12 people are female, equal $42.00 \%$.

\subsection{Description and Analysis of respondents about the Awareness of Social and Environmental}

\section{Accounting}

The awareness of respondents about SEA is reflected in first two points:

"Understanding the meaning of "Social and Environmental Accounting." This point is asked for making sure that the understanding of SEA concept in the real life situation.

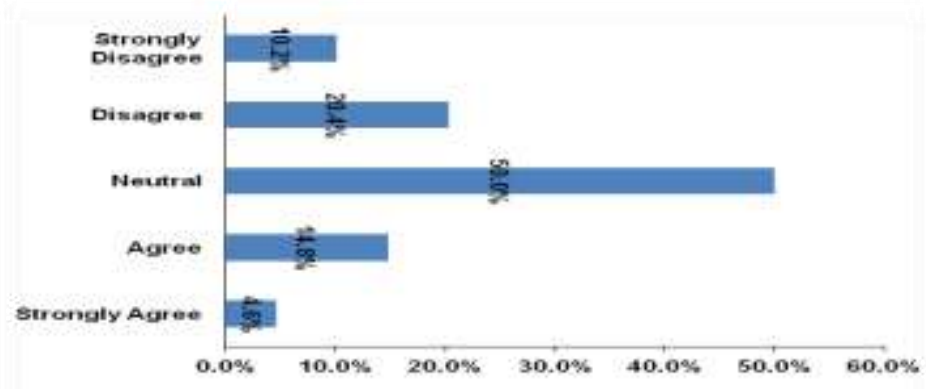

Figure 3: Understanding the meaning of "Social and Environmental Accounting"

Most of the respondents have chosen: "Neutral" Among 28 respondents, only 01 people or $4.6 \%$, chose the answer of "Strongly Agree", 04 people chose the answer of "Agree" or $14.8 \%, 14$ people respondents "Neutral" equal $50.0 \%$, 06 people chose "Disagree" corresponding $20.4 \%$ and $10.2 \%$ or 03 people with the 
most answer is strongly disagree. It means that people in society have little awareness of SEA, which is the first stage to implement SEA to wider range of business.

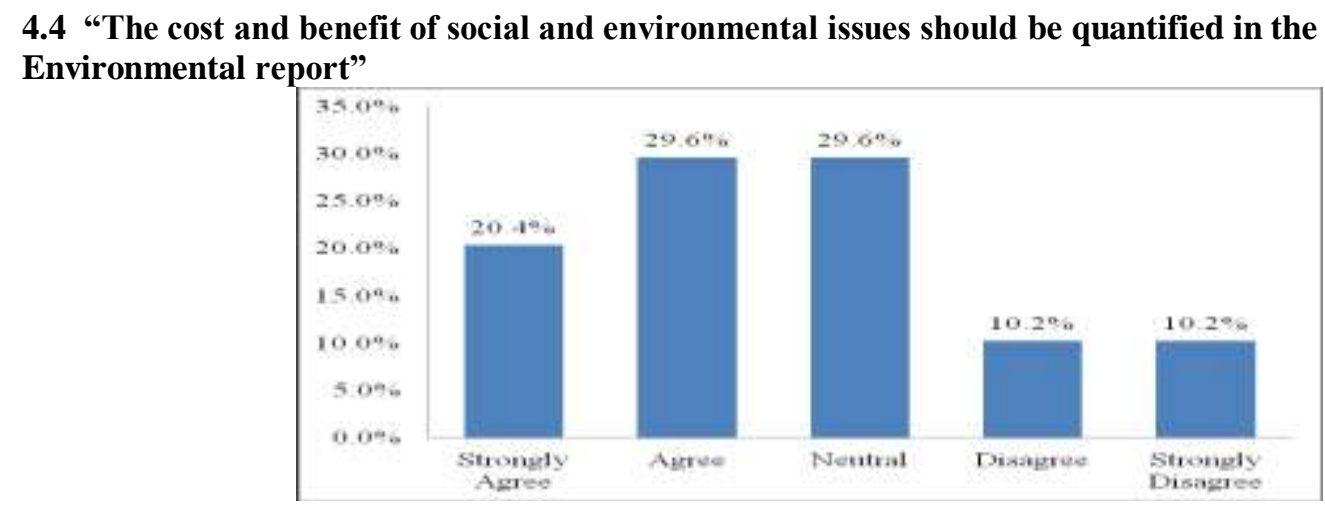

Figure 4: Description of Result - Part II

"The cost and benefit of social and environmental issues should be quantified in the Social and Environmental report?" is the content of above figure. In this figure, respondents chosen among 28 respondents, 06 people or $20.4 \%$ chose the answer of "Strongly Agree", 08 people chose the answer of "Agree" and 08 people respondents "Neutral" or $29.6 \%, 03$ people chose "Disagree" and 03 people with the most answer is strongly disagree or $10.2 \%$. It is visible that a large number of respondents agree with this statement. The social and environmental activities are a part of their company's operation; however, there is lack of quantitative detail such as cost and benefit analysis for SEA.

\section{Recommendation}

1. "We should not consider SEA of the enterprise as a burden, instead of that, we should consider it as opportunity, self-aim, experience in order for the enterprise to operate better, other than a burden of costs, pressure from the State.

2. "We are witnessing the change of consumers all over the world, SEA of enterprises is more and more important and it affirms the operating capacity of enterprises themselves locally and internationally.

3. For Bidar sugar factories in general, BSSK Ltd. in particular, when implementing SEA, enterprises shall have opportunities such as improving their prestige and image among the community and with partners; contribute to enterprises sound culture, thence improve the confidence and attachment of the personnel to the enterprises.

4. High costs for social responsibility shall affect directly business and producing costs, benefit shall be reduced in short-term and even medium-term, but in long-term those costs shall be compensated by benefit brought by SEA.

Therefore, through research with one representative enterprises namely BSSK Ltd., factory should strengthen activities to improve awareness of long-term benefit from applying SEA well in the aim of developing enterprises firmly through workshops sharing experience of big international enterprises and lessons from cases happening in Bidar so far.

\subsection{Suggestion for future research}

With above research topic, if it is carried out better in the future, there will be some more specific experiences as well as plans to improve and give more satisfactory result. Firstly, this research shall be widened more to enterprises, there will be more time to collect survey data, and there will be more approaching methods such as direct interview. In addition, questionnaire will be given more suitably for each subject, and it can be divided each question for each different knowledge level to related problems. Questioning manner shall be simpler, more understandable, and questioning way for each participant shall be paid more attention.

\subsection{Conclusion}

Within the macro view, the environmental protection, business growth and social efficiency, is always in conflict. Also for enterprise, growth pressure or business effect can transgress the environment protection, unless the authorities or consumers interfere. Each product selected by consumers can be considered as a vote for the enterprise. The more votes there are, the better it is for the growth of the enterprise. The problem is whether the consumers are aware of and use selecting right effectively or not. In general, Indian enterprises are mainly medium and small enterprise; therefore, acknowledge and implementation of CSR of each enterprises in India are still limited. Through a small survey, with managers, accountants, employees, and customers of one 
main enterprises, namely BSSK Ltd. it can be found that the acknowledgement of CSR in general and SEA in particular is highly appreciated among those respondents. Measurement of SEA is not nearly formed at Bidar factories, hence there is no specific evaluation approved and there is no numeric concretization. At other role of the society, they appreciate the role of SEA, but they often remain neutral position. According to the above data description and analysis, to some extent we find the awareness, benefit and insufficient problems concerning what measure environmental and social implements in Bidar sugar factories. From data on the internet, press, books, as well as analysis investigation on related subjects of BSSK Ltd., it shows partly the importance of SEA to the long-term and firm development of each enterprise. BSSK Ltd. is aware that it shall not receive and concretize immediately benefit SEA brings to, it will be showed gradually in the business result including cost savings and income increase, reputation improvement and stability of personnel.

\section{References:}

[1] Methodology of Research in Social Sciences by O.R.Krishnaswami and M.Rangaswami.

[2] Http://www.google.com

[3] Collision, D., Lorraine, N. and Power, D. (2004) 'An Analysis of the Stock Market Impact of Environmental Performance Information', Accounting Forum, 28(1) pp.

[4] Creswell, J. W. (2009) Research Design: Qualitative, Quantitative, and Mixed Methods Approaches. Thousand Oaks, California: The Sage Publications. 